Ramon, X., \& Haynes, R. (2019). Sports Coverage on BBC ALBA: Content, Value, and Position in the Scottish Broadcasting Landscape. Communication \& Sport, 7(2), 221-243. https://doi.org/10.1177/2167479518760485

\title{
Sports Coverage on BBC ALBA: Content, Value and Position in the Scottish Broadcasting Landscape
}

\begin{abstract}
Through a mixed-method approach, we examine the sports programming offered by BBC ALBA between 2008 and 2016 and identify the value that the channel creates in Scotland through its diverse sports portfolio. In an increasingly cluttered and complex scenario where pay TV giants Sky and BT hold a plethora of top-tier rights and BBC Scotland and STV cannot fit more sport into their schedules, BBC ALBA serves Gaelic-speaking and national audiences with a regular diet of quality sports programming. Beyond being instrumental to filling schedules, sports content has been a gateway for Gaelic, a key driver of BBC ALBA's investment in the creative sector and a contributor to the development of grassroots sport in Scotland. However, the financial situation under which the channel operates makes it very difficult to sustain and improve its current position. This case study demonstrates that sport broadcasting offers genuine opportunities to maintain linguistic and cultural diversity in small nations, even in a context characterized by escalating competition, dwindling resources and the proliferation of multiple viewing portals.
\end{abstract}

Keywords: BBC ALBA, Scotland, sport, Gaelic, diversity 


\section{Sports Coverage on BBC ALBA: Content, Value and Position in the Scottish Broadcasting Landscape}

Despite the cluttered and "increasingly complex digital media landscape" (Boyle \& Haynes, 2014, p. 85), characterized by the rise and consolidation of video-on-demand platforms (Van den Bulck \& Enli, 2014) and the "intensification of digital media sport content production" (Hutchins, 2011, p. 252), television remains "a compelling platform in delivering shared sporting experiences” (Boyle \& Haynes, 2014, p. 94). As López-González, Stavros, and Smith (2017, p. 186) argue in terms of mainstream television sport, "it might be a digital world, but neither business nor fans have yet abandoned the analogue model". In this article we analyse the opportunities of the minority language channel BBC ALBA to fulfil part of its public service remit through relatively expansive coverage of Scottish sport, often filling the void left by other broadcasters who, for a number of reasons we discuss, have little interest or capacity to cover such events. This case study demonstrates that sport broadcasting offers genuine opportunities to maintain linguistic and cultural diversity in small nations, even in a context characterized by escalating competition, dwindling resources and the proliferation of multiple viewing portals (Lotz, 2014; Smith, 2017). The insights gleaned from the analysis can jointly inform media organizations, policy-makers as well as scholars from around the world.

As it has been extensively documented, "free-to-air broadcasting of sporting events has played a key role in the establishment of sport as a significant part of popular culture" (Smith, Evens, \& Iosifidis, 2015, p. 721). Nevertheless, the vertiginous and "seemingly limitless" escalating value of sports rights in Europe and beyond (Taylor \& Thomass, 2017, p. 116) has left PSBs and commercial free-to-air operators at a disadvantage regarding pay-TV broadcasters and telecommunications operators. 
Smith, Evens, \& Iosifidis (2016, p. 536) highlight the "increasingly prominent position of traditional telecommunications companies, such as British Telecom (UK), Deutsche Telekom (Germany), France Telecom/Orange (France) and Telefonica (Spain), in the contemporary sports media rights market”. Smith, Evens, \& Iosifidis (2015, p. 733) also examined the situation in Australia, Brazil, Italy, India, South Africa, United Kingdom and the United States, concluding that to a greater or lesser degree, "the sports programming market was characterised by the market power of dominant pay-TV broadcasters (i.e. BSkyB, Foxtel, MultiChoice, Sky Italia and TV Globo)". In Canada, players such as TSN (The Sports Network) have left the Canadian Broadcasting Corporation ( $\mathrm{CBC})$ without rights to historically significant events such as the National Hockey League (NHL) and the Canadian Football League (CFL) (Lupien, 2017).

In the UK, the sports broadcasting landscape is dominated by Sky and BT (Smith, 2017). Sky offers more than 80,000 hours of live sports coverage, holding a plethora of top-tier rights, including five of the seven Premier League live packages, the British Masters, rugby's Super League Grand Final and Formula 1 (Sky, 2016). BT, which in 2016 broadcast over 11,000 hours of live sport, holds exclusive rights to the UEFA Champions League and Europa League, as well as offering the Premier League, FA Cup, Premiership Rugby, Moto GP, cricket and WTA tennis (BT Group, 2017). Premium live television coverage of the Scottish Premiership has been shared between Sky and BT since 2013, which followed a period of unsettled competition between Sky, Setanta and ESPN, prior to the intervention of BT Sport as a genuine pay-TV competitor in the UK. The wider commodification of the sports broadcasting market limits the opportunities of the BBC channels to showcase many sporting disciplines, which ultimately restricts their ability to enhance 'cultural citizenship' (Rowe, 2004). Rowe (2018, p. 12) highlights that 'cultural citizenship' in regard to sport "could be described as the rights and responsibilities regarding 
access to, and representation in, sports culture”. As Scherer and Whitson (2009, p. 226)

emphasize, sport "is an issue of cultural citizenship, and thus an important part of the mandate of a public broadcaster". In spite of long-standing state intervention in the UK to protect particular sporting events of 'national significance' on free-to-air television (Boyle, 2013), rights to sport coverage in the UK, like many other countries, is now dominated by global media and telecommunications companies which has undermined the ability of public broadcasters to cover major sporting competitions and leagues. In Scotland, a small nation whose main public service broadcasts are subject to financial, administrative and regulatory control from London, the challenges of meeting the Scottish public's entitlement claims for cultural citizenship around sport coverage are all the greater.

\section{Sport as a Cornerstone of the BBC's Public Service Remit: The Case of Scotland}

Throughout its history, sport has long had a significant role in the BBC's output on radio and television, whether through live outside broadcasts, magazine and highlights formats, studio discussion or documentaries (Haynes, 2016; Whannel, 1992). Through its coverage of major national sporting events such as Wimbledon or the Grand National, or global mega-events such as the Olympic Games, the Corporation has constructed a unique position to provide public value "by bringing communities and/or the nation together and by reaching audiences that are otherwise often underserved by PSBs" (Smith, 2017, p. 213).

In Scotland, the BBC's broader ethos and commitment to the role of sport in the nations' cultural life has also been historically important (Boyle \& Haynes, 1996), albeit increasingly undermined by inflated rights fees and ever-shrinking budgets. Nevertheless, in 2015, BBC One and BBC Two Scotland aired 173.04 hours of sport through its opt-out scheduling from BBC network (BBC Scotland, 2016, p. 3), including Rugby Sevens, the Scottish FA Cup Final, 
shinty’s Macaulay Cup and Camanachd Cup finals, the Australian Open tennis final and the Great Scottish Run. The appetite for sport among Scottish audiences was also reflected in the BBC's live coverage of the Commonwealth Games in 2014, which reached $78 \%$ of the Scottish audience (3.6 million people) (Ofcom, 2015, p. 33).

In spite of the clear cultural cache televised sport has for Scottish audiences, three issues regarding the coverage of Scottish sport prevail. First, the invisibility of live Scottish football in free-to-air schedules (Haynes \& Boyle, 2008), especially of the men's national side, has garnered consistent criticism from fans, public commentators and the Scottish Government. Second, although international rugby is part of the BBC's portfolio of major sports rights, BBC Scotland has received criticism for the failure to pick up rights to domestic Pro12 rugby (The Scotsman, 2008). Third, the media dominance of football in Scottish popular culture has meant that diversity of Scottish sport, both in terms of the range of coverage across sports and the gender gap within sport, has left many sports at the margins of BBC Scotland's programming mix. This situation is particularly stark when one considers the coverage of indigenous sports such as shinty, recognized as a significant contributor to Scotland's sporting heritage (MacLennan, 1993). Certainly, BBC Scotland offers two shinty cup finals per year, but it fails to offer consistent programming of the sport throughout the season. This lack of diversity in sport coverage is by no means exclusive to BBC Scotland, and largely reflects a global universal demand for association football above all else, frequently at the expense of other sports with historic national significance.

The launch of a dedicated minority language channel in Scotland in 2008, with up to seven hours of programming per day, therefore offered new opportunities for sport coverage in Scotland. As our research on BBC ALBA reveals, the channel has strategically bridged the 
aforementioned gaps by filling holes that BBC Scotland has not been able to service, broadcasting "more sport than any other channel" while serving "to normalise Gaelic in usage consumption” (Milligan, Chalmers, Danson, \& Lang, 2011, p. 356-357).

\section{BBC ALBA and Its 'Three Pillars' of Programming}

BBC ALBA is a publicly funded television service managed and delivered by MG ALBA (Meadhanan Gàidhlig Alba, Gaelic Media Scotland) and the BBC. It is the first partnership television service to operate under a BBC licence and regulated by the BBC Trust. Its central aim is to "ensure that persons living in Scotland are provided with a wide and diverse range of high quality programmes in Gaelic" (MG ALBA, 2017a, p. 22).

According to recent data, only a very small proportion $(1.7 \%)$ of the Scottish population (around 90,000 people aged 3 and over) has some language ability in Gaelic (Ofcom, 2017a). However, that does not diminish its cultural significance. In an incomplete basic system where BBC Radio nan Gàidheal and BBC ALBA are the only two existing outlets in Scottish Gaelic (Zabaleta, Ferré-Pavia, Gutierrez, Fernandez, \& Xamardo, 2014, p. 285), the creation of BBC ALBA in 2008 has been a cornerstone for the recovery and normalization of the language (Dunbar, 2012; Manias-Muñoz \& Martori, 2017). The channel has been instrumental in counteracting the fragmented position, the "erratic nature of scheduling" and the lack of variety in Gaelic content in analogue broadcasting (GMS, 2006, p. 12). Currently, BBC ALBA reaches over 700,000 viewers per week.

Through its lifespan, BBC ALBA has showcased programmes of interest and value to both Gaelic and non-Gaelic speakers. From the very beginning, the three core strategic arms of its schedules have been documentaries, music and sport. In nourishing these 'three pillars' of programming, BBC ALBA's contribution to the Scottish creative economy has been noteworthy 
(Manias-Muñoz \& Martori, 2017). In fact, BBC ALBA accounts for half of the commissions from Scottish independent producers and has spent $£ 8.6 \mathrm{~m}$ in the independent sector in 2016 -17 (MG ALBA, 2017a). Despite operating on a tight budget that constrains its expenditure on programming -the money spent on output in 2016 was $£ 16.4 \mathrm{~m}$ (Ofcom, 2017a, p. 36)-, the mix offered by the channel has proved to be successful among audiences.

Since the launch of the channel in September 2008, sport has been essential to filling schedules and attracting a non-Gaelic audience. Reaching a wider population was deemed particularly important regarding the BBC's funding of the channel, for which the BBC set some unrealistic targets given the number of Gaelic speakers in Scotland.

\section{Methodology}

The objective of this research has been to examine the sports programming offered by BBC ALBA and identify how the channel creates value through its sports portfolio. The investigation addresses the following questions:

- $\quad$ RQ1. What is the weight of sports programming in BBC ALBA's schedules?

- $\quad$ RQ2. Why is sport offered by the channel?

- $\quad$ RQ3. How does sports programming provide value for BBC ALBA in terms of its cultural, economic and sporting impact?

For this case study, a mixed-method approach (Bryman, 2016) has been employed. Using content analysis, we systematically examined BBC ALBA's programming schedules from 19 September 2008 to 31 December 2016 (a total of 3,026 days of programming). All the schedules were collected from the BBC's website (http://www.bbc.co.uk/bbcalba/programmes/schedules) 
and codified with information on the proportion of sports content over the entire eight-year period.

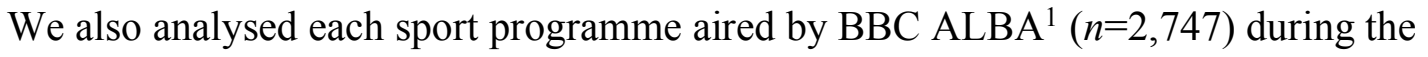
observation timeframe using a set of predetermined categories. Those were classified into the following areas: A) Contextual data (date, weekday, programme name, hour of beginning and ending, duration); B) Agenda (sport, description of the competition or material offered); and C) Production characteristics (live or recorded, original or repeat).

In addition, we conducted four in-depth interviews with experts and decision-makers of BBC ALBA and its affiliated independent production companies who specialize in sport (mneTV and Purple TV). The interviews were used to gain a deeper insight into programme policy and production processes, including: the origins of the channel, the cultural values under which BBC ALBA operates, the strategic vision of BBC ALBA with regard to its sports programming, and the financial resources available.

The four interviewees were: Margaret Mary Murray (BBC's Head of the Gaelic Digital Service), Iseabail Mactaggart (Director of Strategy and Partnership at MG ALBA), Margot McCuaig (director of Purple TV and partner at mneTV) and Hugh Dan MacLennan (BBC ALBA commentator for shinty and rugby and former member of MG ALBA's board). All the conversations were conducted on a face-to-face basis in June 2017, ranging between 50 and 90 minutes in length.

\section{Results}

\section{Scale of Sports Programming at BBC ALBA}

During the timeframe of the observation, BBC ALBA aired over 22,882 hours of programming. Sport accounted for $14.60 \%$ of the programming. In $56.58 \%$ of the days under 
scrutiny (1,712 days), the channel broadcast sports content. As can be seen from Table 1, the weight of sports content remained fairly stable throughout the period. These figures heavily contrast with the situation before the creation of BBC ALBA, when sports content in Gaelic was mostly limited to the news programme Spòrs (mneTV), aired on BBC Two Scotland (GMS, 2006, p. 21) and other productions such as An Caman, Rothair nam Beann and Iomain Samhraidh (GMS, 2008, p. 14).

\section{Sports Agenda at BBC ALBA}

A glance at Table 2 reveals that BBC ALBA has been a platform for a wide sporting menu. The outlet has offered a mix between core sports such as football and rugby, indigenous sports ingrained in Scotland's cultural fabric such as shinty and curling, and a staple diet of traditionally lesser-covered disciplines, most of which remain off the radar in the rest of broadcast stations nationwide.

It is worth noting that live programming has represented just over one fifth $(22.28 \%)$ of the sports content broadcast between 2008 and 2016 (see Table 3). Live coverage primarily focused on rugby and football (Table 4).

\section{A Broader Approach to Football}

Football has received just over half $(51.8 \%)$ of the space within BBC ALBA's sports programming. Beyond first-tier football, the channel has pursued a broader editorial approach by giving exposure to lower-league action and women's football, and by allocating a remarkable space to award-winning football documentaries (see Table 5).

The transmission of football in BBC ALBA has evolved throughout the years as licensing agreements with the Scottish Professional Football League have broadened. In the beginning, 
one Scottish Premiership (previously the Scottish Premier League) game per week was recorded and transmitted later in the day with Gaelic commentary. Following a two-year extension of the deal between MG Alba and SPFL in 2010 (Marshall, 2010), the deferred Saturday games shifted from the $8 \mathrm{pm}$ to the $5.30 \mathrm{pm}$ slot, a movement which "proved very popular indeed" (MG ALBA, 2011, p. 20). For a short time, BBC ALBA was able to offer SPFL three live matches that were not broadcast by Sky or ESPN. When the Clydesdale Bank Premier League folded in 2013, BBC ALBA continued to broadcast certain games live and also offered delayed full-matches of the Ladbrokes Scottish Premiership, but from 2014 onwards the strategy focused solely on offering one-hour edited highlights. From 2017/18 and during three seasons, with the new and improved broadcast agreement with SPFL, BBC ALBA was enabled to show 38 "as live" matches of the Ladbrokes Premiership (MG ALBA, 2017b).

Beyond top-flight football, one of the most distinctive features of BBC ALBA has been the attention devoted to lower leagues and the Scottish Junior football cup final. Since the 2008/09 season, the channel has also retained exclusive rights to broadcast selected matches in the Challenge Cup. Precisely, when Glasgow Rangers was relegated to the third division of the SPFL, BBC ALBA broadcast their first game in the Challenge Cup against Brechin City (MG ALBA, 2013, p. 30). The 'Rangers effect' contributed to attract further audiences nationwide to BBC ALBA:

A significant proportion of our wider audience comes in for football. That is part of our strategy. Why would you watch a Gaelic language channel if you don't have the language? The only reason you would watch it is if there is something of value or interest to you. If you are interested in Championship football in Scotland and you know that your team is going to be on BBC ALBA, you are going to watch BBC ALBA (Murray, personal communication, June 27, 2017).

As Harris and Skillen (2016, p. 92) highlight, "in Scotland, as in many other nations across the globe, female athletes remain under-represented and marginalised within much sports 
media reporting". In contrast, $\mathrm{BBC}$ ALBA has given exposure to the Scotland's women national team through exclusive live coverage. It has also complemented its portfolio with the six-episode series Glasgow FC, matches of the UEFA Women's Champions League and the Scottish Women's Cup Final. McCuaig and Mactaggart comment on BBC ALBA's commitment to women's football, which is essential to shift perceptions of the value of female sport:

$\mathrm{BBC}$ ALBA has done brilliantly in being the only national broadcaster that really commits to live women's sport as a strategic goal. Women's sport has to be normalized and for that to happen people should be able to see it (McCuaig, personal communication, June 15, 2017).

It feels quite comfortable for us to have the approach that we do editorially, because it reflects more honestly what is happening [...] It is about trying to give a different perspective on sport and on Scottish live in general. It is not a linear, mainstream perspective. That editorial prism suits the channel and suits the sport (Mactaggart, personal communication, June 15, 2017).

Other football programmes aired during BBC ALBA's lifespan include the discontinued programme $C l u b T V$ (which provided interviews and behind-the-scenes coverage of Celtic and Glasgow Rangers), historic games and friendly matches. With regards to football documentaries, the most remarkable projects have come from PurpleTV, which will be commented in the section dedicated to half-time feature packages and documentaries.

\section{The Coverage of Pro12 Rugby: A Case of Success}

The sustained coverage of Pro12 rugby (now Pro14) has been another signpost of BBC ALBA. The channel signed its first deal with the SRU in October 2008, which led to the live screening of ten matches of Scottish club rugby during the 2008/09 season (The Scotsman, 2008). In 2010, BBC ALBA reached an agreement to broadcast Pro12 rugby along with S4C and BBC Wales (Wales), RTE and TG4 (Ireland), BBC Northern Ireland and Dhalia TV (Italy) (The Scotsman, 2010). As Hugh Dan MacLennan recalls, "ITV tore up the rugby contract for the Pro 12 because ITV would not allow STV to broadcast rugby on Friday night against the X-Factor". 
This was a chance development that former BBC ALBA's head of content, Alan Esslemont, pounced upon to turn the channel into a success.

Reciprocal arrangements with the aforementioned Welsh, Italian and Irish broadcasters have enabled BBC ALBA to broadcast one or two games per week during each season, including selected away matches involving Glasgow Warriors and Edinburgh Rugby. Murray comments on the value of this fruitful collaboration:

That kind of co-production arrangement that we have with rugby works incredibly well. We share games and we negotiate minority language rights or indigenous language rights as a group. It is a very cost-effective way of delivering coverage and it also ensures that the minority languages have a foothold at high-level competition. For audiences it offers value because we can schedule Welsh games and Irish games if they are of interest and value to the audience in Scotland [...] Sometimes we produce other countries' broadcast and other times they produce our broadcast and we voice over. It is a collaboration on a strategic and a practical level (Murray, personal communication, June 27, 2017).

In addition to that, when in 2014 Sky became the main broadcaster of the Pro12, BBC Alba "instigated an innovative and successful partnership with BBC2 Scotland, sharing coverage between the channels and offering bilingual coverage on both channels" (MG ALBA, 2015: 36). Sharing bilingual personnel, including anchors and commentators, has been positive in terms of resource effectiveness for the organization. Developing broadcast partners in the coverage of rugby also ensures Scottish viewers to BBC ALBA do not miss out on key matches that might not otherwise be possible to cover by the channel on its limited budget.

\section{Shinty: Strengthening the Profile of the 'Sport of Gaels'}

BBC ALBA has devoted great attention to shinty, which accounts for nearly $7 \%(6.69 \%)$ of its sports programming. Since 1990, BBC Scotland had broadcast two or three major finals per year. However, the emergence of BBC ALBA has provided a stronger and more consistent platform for shinty games to be "part of the bigger and wider landscape" (Hugh Dan 
MacLennan, interview). The cultural and heritage links between shinty and Gaelic are viewed as important, and the channel has screened documentaries, such as Lean gu Dlùth, the series Caman, and one-offs such as Gaisgich na Camanachd: Shinty Heroes and SWAGs to showcase the historic importance of the sport to Western Highland popular culture. Although shinty's coverage is far behind the exposure that hurling receives in Ireland, BBC ALBA's commitment to raising the profile of the game, with 8 live matches, should be recognized. As Margaret Mary Murray highlights, "It is really important that the Camanachd Cup final is on the main channel, because that gives it the biggest possible window. But then, for supporters, it is really critical that throughout the remainder of the year there is a level of commitment from other elements of broadcasting, whether it is radio or on BBC ALBA, so that we can support the 'engine room'”. Half-Time Feature Packages and Documentaries: Storytelling at the Core of BBC ALBA's Approach

Mainly through the live coverage of football, rugby and shinty, BBC ALBA and mneTV have excelled in the provision of colourful half-time feature packages. This distinctive element shifts away from the long-established practices and conventions of other broadcasters such as the $\mathrm{BBC}$, Sky or BT, who mostly rely on 'punditry' and the technological advances that they have to deliver the coverage. As McKenna (2016) argues, BBC ALBA “dispenses with the tired, decades-old format, favoured by the BBC, of spoiling the half-time interval with worthless, predictable and semi-literate nonsense by former footballers. Instead, there are minidocumentaries behind the scenes at the clubs. It is sharp and innovative, unlike the coverage on BBC Scotland". As Iseabail Mactaggart argues, "We don't want to be BT Sport. We are interested in the human stories and the human aspects of the sports coverage. That is an important part of the legacy that we are building up within BBC ALBA”. 
Along with half-time packages, sports documentaries have promoted original angles and unique perspectives to Scottish and international sport. The interest in revisiting evocative human stories woven into the Scottish shared sports culture has been a constant feature in BBC ALBA's approach. The mix of contemporary and historical footage, well-narrated stories and interviews have been key ingredients of the success of the award-winning works produced by the independent sector, particularly, by PurpleTV, a small company run by Margot McCuaig and Allan MacDonald. Salient examples here include Gothenburg '83 (focused on the season Sir Alex Ferguson led Aberdeen FC to European glory), Honeyballers (on the history of Scottish women's football), Famous Five (on Hibernian's FC recognized post-war forward line) or the portrayals of the football legends Jock Stein, Jimmy Johnstone and Jim Baxter. All those compelling stories, created within a tight budget (each documentary costs between $£ 42,500$ to $£ 60,000)$, contribute to create cultural value in Scotland:

One of the important things about the stories I have been telling via Purple TV is that they aren't necessarily about sport, they are about people. They are about elements that are key to our social, our cultural and our emotional past [...] Generally, stories have been about people that have achieved great things but that also have to face tragedy. These stories are hugely important to who we are culturally (McCuaig, personal communication, June 15, 2017).

Beyond PurpleTV's projects, the documentaries created by macTV for the Soillse series have included stories on world football, long-distance running in Kenya, the Amazon Games, base jumping, climbing, free diving, horse riding, rodeo, camel racing in Niger and even Florentine football.

\section{Sheepdog Trials: a Popular Sport with Great Exposure at BBC ALBA}

Sheepdog trials have been the third sport with more airtime in BBC ALBA (over 271 hours), accounting for $8.14 \%$ of its portfolio. Although this might seem surprising, it should be taken into account that sheepdog trials are a rural sport with a long tradition in the UK (Urdank, 
2006), as well as in other countries such as New Zealand, Australia, Canada or Ireland. Its popularity “can, at least in part, be attributed to the cult BBC TV series 'One Man and His Dog', which brought the thrills of sheepdog trials to the living room of millions" (Collins, Martin, \& Vamplew, 2005, p. 242). While other channels have discontinued its relationship with the sport, BBC ALBA has committed to sheepdog trials with the long-run series Farpaisean Chon-

Chaorach. The programme, presented by Donald Macsween and Catriona Macphee, includes highlights from the championships across the UK and Ireland, while providing a behind-thescenes insight into its protagonists through self-contained little films. Produced by mneTV, each season consists of eight programmes, which are later repeated throughout the year. McCuaig reflects on the elements that have made this programme so appealing among audiences:

One of the things that is a really big driver in the sheepdog trials is the competitiveness of it. That is balanced against with the tranquility of it, and you do find yourself absolutely getting lost in it. We didn't focus quite so much on the competition of element of it in the early days, but we realized that that had to be fundamental to it to grow, because you have to be rooting for a winner. The community really loves it (McCuaig, personal communication, June 15, 2017).

The enduring relationship between BBC ALBA and sheepdog trials remains vibrant as Nemeton TV has been in charge of producing the tenth series of Farpaisean Chon-Chaorach, using many of the same freelance production crew previously used by mneTV, which premiered in January 2018.

\section{Curling: Showcasing another Truly Scottish Sport}

Curling is one of the three truly Scottish indigenous sports, along with shinty and golf (MacLennan, 1998). It exists from the middle of the sixteenth century and "was the national passion until it was displaced by football at the end of the century" (Collins et al., 2005, p. 238). However, its current popularity in Scotland and beyond is unquestionable. Drawing on its appeal, 
BBC ALBA incorporated curling in 2016, offering the Perth Curling Masters and the Women's International Masters. For mneTV, the live coverage of these prestigious tournaments represented a challenge both in technical and talent grounds, but the audiences responded well to it:

Everybody demonstrated in Scotland that people like curling. It is very hypnotic, you can pick out somebody that you like and then you can follow them to a conclusion. It was challenging as there were long shifts. We learned quite a bit from that and we built on for the second production that we did. It was really nice to see so much feedback in social media as well" (McCuaig, personal communication, June 15, 2017).

This live coverage at BBC ALBA, supplemented by live internet streaming of one game in each draw, consolidated the profile of these two tournaments while generating new opportunities for sponsors and partners connected to the sport, with new key commercial deals announced with drinks manufacturer Go Coco in 2016 and the opticians Specsavers in 2017.

\section{Discussion}

While pay TV giants Sky and BT control the most valuable rights and BBC Scotland and STV cannot fit more sport into their schedules, BBC ALBA serves Gaelic-speaking and national audiences with a regular diet of quality sports programming that cannot be found elsewhere. As an essential part of its public service remit, the channel gives exposure to Scottish football and rugby while lending space to indigenous sporting manifestations such as shinty and curling. This detailed attention to autochthonous sport connects with the strategies pursued by other broadcasters in small countries in Europe, such as RTÉ - Raidió Teilifís Éireann- (Connolly \& Dolan, 2012) or NRK -Norwegian Broadcasting Corporation-(Røssland, 2017), which have made a distinctive contribution in terms of showcasing culturally-important practices such as Gaelic Football, Hurling and Camogie (Ireland) or Nordic skiing and jumping (Norway). This 
signpost demonstrates that in a context of "transnational flows and global connectivities" (Rowe, 2018, p. 24), sports broadcasting is not completely "overridden by the global" (Rowe, 2013, p.

2). Through its localised and strategically astute intervention in sport coverage BBC ALBA has generated a threefold benefit to minority language broadcasting in Scotland and Gaelic culture more broadly.

\section{Sports Programming as a Positive Asset for the Language}

First, sport has been instrumental in BBC ALBA's strategy of raising the profile of Gaelic. As Iseabail Mactaggart highlights, "it is important that Gaelic isn't a 'rarified other' thing. Sport is a hugely effective way of making Gaelic accessible". It is true that the extent of Gaelic commentary in sports programming has been controversial. While football is mostly broadcast in Gaelic, in rugby the coverage is bilingual, with the expert summariser usually speaking in English. The balance is approximately $60 / 40$ to 50/50, with the aim of retaining the non-Gaelic audience. This is an area of contention amongst some members of the Gaelicspeaking community who consider that BBC ALBA should be an exclusive channel for Gaelic language output (Hugh Dan MacLennan, interview).

That being said, sport has been fundamental to the recovery and enhancement of the Gaelic lexicon. To illustrate, MacLennan has gone back into the language to find and coin words to translate some of the technical terms of the sport, broadening viewers' knowledge and understanding of the language. He also developed an extensive glossary for internal and school use, Gnàthasan-cainnt is eile son prògraman spòrs (Guidelines for terminology in sports programmes). MacLennan reflects on the process of resurrecting Gaelic in sport:

We had to develop the vocabulary for rugby, but we had to do it for shinty and football as well. I looked at what the South Africans did, the French did, the Maoris did. I also had to invent words and I also had to find old words. I found a really old word which I use for stand-off, which is a swivel. And that word 
"udalan" now has come back into the vocabulary and is used regularly. People don't care where the words come from, but start to use them in different contexts. The sheepdog trials are the same, because that has a whole set of vocabulary in Gaelic. Kids pick that up very quickly and those words are being used again (MacLennan, personal communication, June 12, 2017).

The coverage of sport can also contribute to alter people's attitudes on Gaelic, as Murray highlights:

If you are a non-Gaelic speaker and the only way that you can get rugby or the Junior Cup is by watching BBC ALBA, that is providing a useful service. And I hope that by providing a useful service, that that will impact on your perspective on the language. If it is a negative one, it will shift into something of a more neutral perspective if not into a more positive perspective (Murray, personal communication, June 27, 2017).

McGonagle (2011) argues for the need to protect the cultural and linguistic identity of minority language groups. In this regard, BBC ALBA reveals the benefit sport coverage can bring to minority language broadcasters and how the nuanced uses of minority language commentaries on popular sports can help maintain a broader visibility of the language in small nations where the dominant language is the overwhelming language in which most media operate.

\section{BBC ALBA as a Catalyst for the Growth of Grassroots Sport}

Second, BBC ALBA has given sporting organizations and governing bodies a unique value in terms of production exposure. As MacLennan argues, the channel "gives them eyeballs. They might not get the income, but they do get exposure. It helps sport economically, because organizations can sell that exposure to sponsors', BBC ALBA should also be credited as a central agent in helping grassroots sport across Scotland:

There are a hundred and twenty children playing shinty at lunchtime at Linlithgow Academy, which is just completely outside the shinty playing area. Part of that is that they see it on television. They see it and think 'I can be the next Ronald Ross' [...] In cultural terms, it is visibility, it is normalization, it is part of our sporting culture (MacLennan, personal communication, June 12, 2017). 
Rugby is interesting because you can see what a broadcaster can do as a kind of game developer within the country. Scotland doesn't have the same history in terms of rugby than for example, Wales. Doing the Pro12 has been really interesting to see how that has grown. There is no doubt that having a strong indigenous national broadcaster has been an important part of it (Mactaggart, personal communication, June 15, 2017).

BBC ALBA demonstrates that public broadcasters in small nations can be good strategic partners to sports organizations in helping grow grassroots sports. By raising the awareness and profile of many disciplines, minority broadcasters can help to boost the citizens' interest in a myriad of sporting practices ingrained in the country's cultural fabric.

\section{Sport as a Key Driver of BBC ALBA's Impact on Creative Economy}

Third, as noted beforehand, BBC ALBA is recognized for its impact on the independent production sector. Sport has been a key driver of that impact, as can be seen in the figures regarding production payments by genre (Table 6). The total spent on sports has been remarkable, proving to be very efficient in terms of cost per hour. Since its inception, mneTV has received $\mathrm{BBC}$ ALBA's highest allocation of payments, ranging between $21.6 \%$ and $32.9 \%$ of the total spent on programme development between the financial years 2008/09 and 2016/17.

\section{Has BBC ALBA Reached a Glass Ceiling?}

Despite the value generated by BBC ALBA's sports programming, the situation under which the channel operates makes it very difficult to sustain and improve its current position. According to Smith (2017, p. 204), "the ability of PSBs to utilise sports programming to enhance "cultural citizenship"" in the present context is "increasingly under threat from a combination of the escalating cost of sports rights and a squeeze on their own finances/remit”. Since its inception, the funding of the channel has been limited in comparison to the money received by other broadcasters such as S4C (BBC-MG ALBA, 2009, p. 24). The BBC "has committed to 
raise its annual spend on BBC ALBA by $£ 1.2 \mathrm{~m}$ ” (MG ALBA, 2017a, p. 7), reaching $£ 7.8$ million, but its contribution remains modest. We should remember that $\mathrm{S} 4 \mathrm{C}$ currently receives $£ 75 \mathrm{~m}$ of funding from the licence fee as well as a BBC expenditure of $£ 29.2 \mathrm{~m}$ on additional content (Ofcom, 2017b, p. 33). It should be noted that in a context of dwindling financial resources and increasing pressures, minority language broadcasters across Europe are struggling to sustain their position and output (Azurmendi, 2013; Zabaleta, Ferré-Pavia, Gutierrez, Fernandez, \& Xamardo, 2014).

As Mactaggart argues, "the problem of underfunding is that the potential of the channel to be a showcase for Gaelic and the riches of Gaelic is reduced". Under the current funding settlement, only 1.8 hours of originations per day are possible, in contrast to 8 hours in S4C (S4C, 2015). The high volume of repeats at BBC ALBA (currently three out of four programmes are repeats) can lead to 'viewer fatigue'. As can be perceived from Table 7, repeats are also an issue in sports programming. While live or deferred coverage of matches has a 48-hours maximum repeat value (Margaret Mary Murray, interview), one-off documentaries and series are commissioned as properties that can be repeated over time. Although the volume of repeat material has been reduced over the years, it should be noted that "there has not been a specific strategy, the changes have been driven by the nature of rights" (Iseabail Mactaggart, interview).

\section{Opportunities and Challenges Ahead}

Despite the fact that financial resources have not and look unlikely to grow, new opportunities could come with the new agreement between BBC ALBA and the Irish company Nemeton TV. After being in charge of sports production since the inception of the channel, mneTV voluntarily closed operations in the end of June 2017 following the retirement of its managing director to make way for new creative talent to emerge within the independent sector. 
As Margaret Mary Murray explains, "they have changed the sports production model in Scotland. They have proved that on a very tight budget you can produce attractive sports programming”. McCuaig, now working with Nemeton, explained the opportunities that the new company could bring:

They are huge, they have been doing GAA for 20 or more years. They are very strong in developing production talent in Irish, they also run a diploma course as well $[. .$.$] I hope that looking forward is in their plans to try and develop$ production talent alongside BBC ALBA. They are also big in the internationalization aspect, which hopefully will bring some rewards in terms of development (McCuaig, personal communication, June 15, 2017).

Cross-fertilization and cooperation with Ireland, through Nemeton and TG4, is seen as a very fertile piece of ground to continue broadening BBC ALBA's sporting agenda (Hugh Dan MacLennan, interview). Gaelic football and hurling could be potentially attractive to Scottish audiences and the new relationship with Nemeton might help BBC ALBA to explore new avenues. The reciprocal scheduling of hurling and shinty finals "would also expose us to our cultural relationship with Ireland a little bit better”, MacLennan adds.

In the current context, BBC ALBA faces key challenges. Those include: regaining visibility on "a densely populated iPlayer" (MG ALBA, 2017a, p. 15), solving poor broadband in many Gaelic-speaking areas, enhancing internationalization, and implementing a new social media strategy. Arguably, the most important challenge for BBC ALBA is the launch of the new BBC Scotland channel in autumn 2018. As McCuaig argues, "There would need to be a lot of work done between both assets to ensure that each will keep its distinctiveness. BBC ALBA has worked very hard to create its distinctiveness, its individuality, its audiences, its ethos. They will really need to fight hard to hang on to that". How BBC ALBA can maintain its distinctive role as a minority language broadcaster of sport in a small and squeezed national broadcasting 
environment will require continued political and financial support from the Scottish Government and the BBC.

\section{Conclusion}

This case study on BBC ALBA raises important issues for the role of PSBs in promoting socio-cultural value through sports broadcasting in this age of 'digital plenitude' (Hutchins \& Rowe, 2009). In a time when Public Service Television is increasingly "under threat in the liberalized and digitalized market" (Røssland, 2017, p. 159) and when the tensions between the global and the nationally and regionally specific cultural practices (Rowe, 2013) are noteworthy, BBC ALBA has proved to be a truly Scottish channel, which occupies a distinctive position within the country's sports broadcasting scenario. The research has shown that, through its broad and diverse portfolio, the channel provides sports content that the audience does not get anywhere else and does it free-to-air. In a channel driven by cost per hour, sport has been a key part of fulfilling BBC ALBA's obligations to the BBC and its funding. Spotting and delivering opportunities in sports terms has been instrumental in expanding its audience across the board. Beyond that, the research highlights the significance of the channel in terms of sustaining the Gaelic language community, giving visibility to nationally specific sporting practices and offering support to the small but resilient production sector in Scotland. The importance of these wider impacts should not obscure that certain areas should be carefully addressed, including the overreliance on repeats and the current English/ Gaelic commentary balance. To bridge these gaps and help to improve BBC ALBA's position across all genres, a stronger political support and increased funding by the BBC is deemed to be essential.

Beyond the locally specific factors that are important in understanding this particular case, the insight provided by BBC ALBA has broader relevance. This case study reveals that 
'digital plenitude' -the broadening of communication channels afforded by digital media and the Internet- provides opportunities to broaden the spectrum of sport broadcasting in small nations due to the relatively low cost of production and distribution channels. Minority language broadcasters can leverage their 'special status', in cultural and public policy terms, to develop partnerships with mainstream sports which operates in tandem rather than in competition with mainstream broadcasters of sport who hold the primary television rights. In this sense, minority language sport broadcasting is non-rivalrous with mainstream sport channels and coverage because it is meeting a different set of cultural demands. The case of BBC ALBA reveals it is possible for governing bodies of sport to broaden the plurality of their media partnerships without undermining the value of the primary rights to their sport.

However, for public service models of minority language broadcasting from sport to survive it requires a supportive policy environment and public investment. It also requires an understanding from governing bodies of sport - especially football and other dominant sportsthat minority language media provide opportunities for them to broaden their reach to diverse audiences, as well as servicing the demand of 'mainstream' audiences for sport who are willing to forego commentaries in the de facto official language of a nation to view their favourite sport.

Future research must continue monitoring the coverage of sport at BBC ALBA in order to examine the patterns of continuity and change in its programming schedules. With the creation of the new BBC Scotland Channel in 2018, it will be particularly timely to trace the evolution of sport in both outlets to see how both television channels maintain their distinctiveness. In order to do it, conducting further interviews on the production side will be necessary. In addition to that, it will be fruitful to engage in conversations with both Gaelic-speaking and non-Gaelicspeaking viewers. Ethnographic data concerning audience reception will allow researchers to 
know more about their expectations and outcomes with regard to the consumption of sports programming at BBC ALBA.

Beyond Scotland, this work can act as a springboard for future examinations of the role of sports coverage in minority language broadcasters in terms of promoting cultural citizenship, an area which remains largely under-researched. It will be worth to analyse the operations and specific practices of other broadcasters serving minority language communities and small nations in Europe and beyond. In particular, it is necessary to interrogate how organizations such as TG4 (Ireland), S4C (Wales), EITB (Basque Country), CCMA (Catalonia) or NRK (Norway), to list a few, support indigenous sport while providing cultural and economic value in their territories. Attending the traditions and peculiarities of each context can help to advance true understandings of the role of sport in minority language broadcasting, which could jointly inform policy-makers, media organizations as well as scholars from around the world. 


\section{Notes}

1. It has been beyond the scope of this research to examine the sports news included in the daily bulletin An Là. 


\section{References}

Amezaga J., Arana, E., Narbaiza, B., \& Azpillaga, P (2013). The public sphere and normalization of minority languages. An analysis of Basque television in light of other experiences in Europe. Trípodos, 32(1), 93-112.

Azurmendi, A. (2013). Reforms to the European regional minority-language television corporations in the current context of crisis. Revista Latina de Comunicación Social, 68, $355-382$.

BBC-MG ALBA. (2009). Performance, partnerships and future strategy. London, UK: BBC Trust.

BBC Scotland. (2016). BBC Scotland annual review 2015/16. London, UK: BBC.

Boyle, R. (2013). No Longer the crown jewels of sport? Television, sport and national events in the UK. In J. Scherer \& D. Rowe (Eds.), Sport, Public Broadcasting and Cultural Citizenship. Series: Routledge Research in Sport, Culture and Society: Signal Lost? (pp. 110-127). London, UK: Routledge.

Boyle, R., \& Haynes, R. (1996). 'The grand old game': Football, media and identity in Scotland. Media, Culture \& Society, 18(4), 549-564.

Boyle, R., \& Haynes, R. (2014). Watching the games. In V. Girginov (Ed.), Handbook of the London 2012 Olympic and Paralympic games, vol. 2: Celebrating the games (pp. 84-95). Abingdon: Routledge.

Bryman, A. (2016). Social research methods. Oxford, UK: Oxford University Press. BT Group. (2017). BT group PLC annual report \& form 20-F 2017. London, UK: BT Group. Collins, T., Martin, J., \& Vamplew, W. (2005). Encyclopedia of traditional British rural sports. Abingdon: Routledge. 
Connolly, J., \& Dolan, P. (2012). Sport, media and the Gaelic Athletic Association: the quest for the "youth" of Ireland. Media, Culture \& Society, 34(4), 407-423.

Dunbar, R. (2012). BBC ALBA and the evolution of Gaelic television broadcasting: A case study. European Yearbook of Minority Issues Online, 9(1), 389-418.

GMS. (2006). Annual report \& accounts. Stornoway: Gaelic Media Service.

GMS. (2008). Annual report \& accounts. Stornoway: Gaelic Media Service.

Harris, J., \& Skillen, F. (2016). Sport, gender and national identities. In N. Blain \& D. Hutchinson (Eds.), Scotland's referendum and the media: National and international perspectives (pp. 83-93). Edinburgh: Edinburgh University Press.

Haynes, R. (2016). BBC sport in black and white. London, UK: Palgrave Macmillan UK.

Haynes, R., \& Boyle, R. (2008). Media sport. In N. Blain \& D. Hutchinson (Eds.), The media in Scotland (pp. 253-270). Edinburgh: Edinburgh University Press.

Hutchins, B. (2011). The acceleration of media sport culture: Twitter, telepresence and online messaging. Information, Communication \& Society, 14(2), 237-257.

Hutchins, B., \& Rowe, D. (2009). From Broadcast Scarcity to Digital Plenitude: The Changing Dynamics of the Media Sport Content Economy. Television \& New Media, 10(4), 354370.

López-González, H., Stavros, C., \& Smith, A. C. T. (2017). Broadcasting sport: Analogue markets and digital rights. International Communication Gazette, 79(2), 175-189.

Lotz, A.D. (2014). The Television Will Be Revolutionized. New York: New York University Press. 
Lupien, P.A. (2017). Sport and public service in Canada: The roots of the inherent bonds between the Canadian Broadcasting Corporation/Radio-Canada and the Olympic Games. International Communication Gazette, 79(2), 120-134.

MacLennan, H. D. (1993). Shinty! celebrating Scotland's game. Nairn: Balnain Books.

MacLennan, H.D. (1998). Shinty's place and space in world sport. The Sports Historian, 18(1), $1-23$.

Manias-Muñoz, M., \& Martori, A. (2017). BBC ALBA: Servicio público y representación gaélica en Escocia. Historia y Comunicación Social, 22, 191-206.

Marshall, A. (2010, 16 April). SPL extend deals for BBC coverage. Daily Record, p. 79.

McGonagle, T. (2011). Minority Rights, Freedom of Expression and the Media: Dynamics and Dilemmas. Antwerp, Belgium: Intersentia.

McKenna, K. (2016). BBC ALBA must not be allowed to wither for lack of cash. Retrieved from https:/www.theguardian.com/commentisfree/2016/sep/11/bbc-alba-not-allowed-towither-lack-of-funds

MG ALBA (2008, 2009, 2010, 2011, 2012, 2013, 2014, 2015, 2016, 2017a). Annual Reports \& Statement of Accounts. Stornoway: MG ALBA.

MG ALBA. (2017b). SPFL announces new and improved broadcast deal with BBC ALBA. Retrieved from http://www.mgalba.com/news/2017/spfl-bbcalba-deal-29-0617.html?lang=en

Milligan, L., Chalmers, D., Danson, M., \& Lang, A. (2011). BBC ALBA's contributions to Gaelic language planning efforts for reversing language shift. Current Issues in Language Planning, 12(3), 349-361.

Ofcom. (2015, 2017a). Communications market report: Scotland. London, UK: Ofcom. 
Ofcom. (2017b). Communications market report: Wales. London, UK: Ofcom.

Røssland, L. A. (2017). Sports - nation - television: The cultural dimension of the Listed Events history in Norway. International Communication Gazette, 79(2), 148-161.

Rowe, D. (2004). Watching brief: Cultural citizenship and viewing rights. Sport in Society, 7(3), 385-402.

Rowe, D. (2013). Reflections on Communication and Sport: On Nation and Globalization. Communication \& Sport, 1(1-2): 18-29.

Rowe, D. (2018). Cultural citizenship, media and sport in contemporary Australia. International Review for the Sociology of Sport, 53(1): 11-29.

S4C. (2015). Annual report \& statement of accounts for the 12 month period to 31 March 2015. Cardiff: S4C.

Sky. (2016). Annual report 2016. Isleworth: Sky plc.

Scherer, J. \& Whitson, D. (2009). Public broadcasting, sport, and cultural citizenship: The future of sports on the Canadian Broadcasting Corporation? International Review for the Sociology of Sport, 44(2-3), 213-229.

Smith, P. (2017). Playing under pressure: Sport, public service broadcasting and the British Broadcasting Corporation. International Communication Gazette, 79(2), 203-216.

Smith, P., Evens, T., \& Iosifidis, P. (2015). The regulation of television sports broadcasting: A comparative analysis. Media, Culture \& Society, 37(5), 720-736.

Smith, P., Evens, T., \& Iosifidis, P. (2016). The next big match: Convergence, competition and sports media rights. European Journal of Communication, 31(5), 536-550. 
Taylor, G., \& Thomass, B. (2017). Sports rights and public service media/public broadcasting: Case studies on economic and political implications. International Communication Gazette, 79(2), 111-119.

The Scotsman. (2008). Scottish clubs agree to BBC ALBA showing ten games live. Retrieved from http://www.scotsman.com/sport/scottish-clubs-agree-to-bbc-alba-showing-tengames-live-1-1135348

The Scotsman. (2010). BBC ALBA fills the TV gap with tranche of matches. Retrieved from http://www.scotsman.com/sport/bbc-alba-fills-the-tv-gap-with-tranche-of-matches-1809280

Urdank, A. M. (2006). The rationalisation of rural sport: British sheepdog trials, 1873-1946. Rural History, 17(1), 65-82.

Van den Bulck, H., \& Enli, G. S. (2014). Flow under pressure: Television scheduling and continuity techniques as victims of media convergence? Television \& New Media, 15(5), $449-452$.

Whannel, G. (1992). Fields in Vision. Television sport and cultural transformation. London, UK: Routledge.

Zabaleta, I., Ferré-Pavia, C., Gutierrez, A., Fernandez, I., \& Xamardo, N. (2014). European minority language media and journalism: Framing their marginal reality. International Communication Gazette, 76(3), 275-295. 


\section{Tables}

Table 1

Scale of Sports Programming at BBC ALBA

\begin{tabular}{|c|c|c|c|}
\hline Year & All programming & Sports programming & $\%$ \\
\hline 2008 & 730:55:00 & $120: 55: 00$ & 16.54 \\
\hline 2009 & 3,130:42:00 & $370: 15: 00$ & 11.83 \\
\hline 2010 & 2,647:42:00 & $436: 15: 00$ & 16.48 \\
\hline 2011 & 2,707:21:00 & $385: 15: 00$ & 14.23 \\
\hline 2012 & $2,731: 56: 00$ & $442: 40: 00$ & 16.20 \\
\hline 2013 & $2,717: 11: 00$ & 419:05:00 & 15.42 \\
\hline 2014 & 2,710:23:00 & 429:20:00 & 15.84 \\
\hline 2015 & $2,731: 15: 00$ & $354: 40: 00$ & 12.99 \\
\hline 2016 & $2,775: 25: 00$ & $381: 25: 00$ & 13.74 \\
\hline Total & 22,882:50:00 & 3,339:50:00 & 14.60 \\
\hline
\end{tabular}

Source: Authors' analysis. 
Table 2

Sports Agenda at BBC ALBA

\begin{tabular}{|c|c|c|}
\hline Sport & Duration & $\%$ \\
\hline Athletics & 06:05:00 & 0.18 \\
\hline Base jumping & 03:30:00 & 0.10 \\
\hline Boxing & 05:25:00 & 0.16 \\
\hline Camel racing & 02:45:00 & 0.08 \\
\hline Climbing & $25: 10: 00$ & 0.75 \\
\hline Commonwealth Games & 6:00:00 & 0.18 \\
\hline Curling & $42: 35: 00$ & 1.28 \\
\hline Cycling & $31: 10: 00$ & 0.93 \\
\hline Diving & 03:40:00 & 0.11 \\
\hline Florentine Football & 03:40:00 & 0.11 \\
\hline Football & $1,729: 50: 00$ & 51.79 \\
\hline Golf & 00:30:00 & 0.01 \\
\hline Highland Games & 21:00:00 & 0.63 \\
\hline Horse riding & 04:15:00 & 0.13 \\
\hline International Island Games & 16:00:00 & 0.48 \\
\hline Kayaking & 06:00:00 & 0.18 \\
\hline Martial arts & 01:20:00 & 0.04 \\
\hline Motorsports & $185: 20: 00$ & 5.55 \\
\hline
\end{tabular}




\begin{tabular}{|c|c|c|}
\hline Multi-sports & $52: 25: 00$ & 1.57 \\
\hline Orienteering & 05:00:00 & 0.15 \\
\hline Other adventure sports & $17: 25: 00$ & 0.52 \\
\hline Recreational fishing & $91: 05: 00$ & 2.73 \\
\hline Rodeo & 07:00:00 & 0.21 \\
\hline Rowing & 08:30:00 & 0.25 \\
\hline Rugby & $538: 30: 00$ & 16.12 \\
\hline Sailing & 05:05:00 & 0.15 \\
\hline Sheepdog Trials & 271:50:00 & 8.14 \\
\hline Shinty & $223: 20: 00$ & 6.69 \\
\hline Shooting & 05:55:00 & 0.18 \\
\hline Skydiving & 03:30:00 & 0.10 \\
\hline Surfing & 07:15:00 & 0.22 \\
\hline Swimming & 08:45:00 & 0.26 \\
\hline Total & 3,339:50:00 & 100.00 \\
\hline
\end{tabular}


Table 3

Live and Non-Live Sports Content Broadcast at BBC ALBA

\begin{tabular}{lcc}
\hline & Duration & \% \\
\hline Live sport content broadcasting & $744: 10: 00$ & 22.28 \\
Non-live sport content broadcasting & $2,595: 40: 00$ & 77.72 \\
\hline Total & $\mathbf{3 , 3 3 9 : 5 0 : 0 0}$ & $\mathbf{1 0 0 . 0 0}$ \\
\hline
\end{tabular}

Source: Authors' analysis. 
Table 4

Live Sports Content Aired at BBC ALBA

\begin{tabular}{lcc}
\hline & Duration & \% \\
\hline Curling & $42: 35: 00$ & 5.72 \\
Football & $291: 30: 00$ & 39.17 \\
Orienteering & $03: 50: 00$ & 0.52 \\
Rugby & $322: 40: 00$ & 43.36 \\
Shinty & $83: 35: 00$ & 11.23 \\
\hline Total & & \\
\hline
\end{tabular}

Source: Authors' analysis. 


\section{Table 5}

Football Agenda at BBC ALBA

\begin{tabular}{|c|c|c|}
\hline Type of football programme & Duration & $\%$ \\
\hline Scottish Premier League / Scottish Premiership (First tier) & 1,087:00:00 & 62.84 \\
\hline Football Documentaries & $165: 50: 00$ & 9.59 \\
\hline Scottish First Division / Scottish Championship (Second tier) & 115:50:00 & 6.70 \\
\hline Scottish Challenge Cup matches & 100:05:00 & 5.79 \\
\hline Football Discussion \& Talk programmes & 64:00:00 & 3.70 \\
\hline Scotland Women's National Team matches & $47: 25: 00$ & 2.74 \\
\hline Historic matches & $35: 05: 00$ & 2.03 \\
\hline Scottish Second Division / Scottish League One (Third tier) & 34:05:00 & 1.97 \\
\hline Scottish Junior Cup matches & 25:25:00 & 1.47 \\
\hline Friendly matches & $16: 55: 00$ & 0.98 \\
\hline Scotland U21 matches & 10:55:00 & 0.63 \\
\hline UEFA Women's Champions League matches & 10:20:00 & 0.60 \\
\hline Women's Scottish Cup & 07:30:00 & 0.43 \\
\hline Scottish League Two matches (Fourth tier) & 04:10:00 & 0.24 \\
\hline Scotland National Team matches & 02:25:00 & 0.14 \\
\hline Scottish Youth Cup matches & 02:20:00 & 0.13 \\
\hline UEFA Champions League & 00:30:00 & 0.03 \\
\hline Total & 1,729:50:00 & 100.00 \\
\hline
\end{tabular}


Table 6

Production Payments by Programme Genre

\begin{tabular}{lrrr}
\hline Programme genre & Expenditure & Equivalent hours & Cost per hour \\
\hline Sport & $15,479,624$ & 1407 & $11,001,86$ \\
Arts \& Entertainment & $23,013,323$ & 775,8 & $29,663,99$ \\
Children & $8,922,556$ & 549,8 & $16,228,73$ \\
Drama \& Comedy & $5,024,192$ & 19,1 & $263,046,70$ \\
Factual & $27,528,401$ & & $28,013,03$ \\
Religion & $1,148,974$ & 982,7 & $27,356,52$ \\
Radio & 585,187 & 42 & $1,080,48$ \\
Education \& Learning & 43,000 & 541,6 & $43,000,00$
\end{tabular}

Source: Authors' analysis of MG ALBA annual reports (MG ALBA, 2008, 2009, 2010, 2011, 2012, 2013, 2014, 2015, 2016, 2017a). 


\section{Table 7}

Original and Repeat Sports Programming Broadcast at BBC ALBA (2008-2016)

\begin{tabular}{llc}
\hline & Hours & $\mathbf{\%}$ \\
\hline Original sport content broadcasting & $1,596: 15: 00$ & 47.79 \\
Repeat sport content broadcasting & $1,743: 35: 00$ & 52.21 \\
\hline Total & $\mathbf{3 , 3 3 9 : 5 0 : 0 0}$ & $\mathbf{1 0 0 . 0 0}$
\end{tabular}

Source: Authors' analysis. 